found. Cne of the most important matters contained in the book is the author's account of a Bathybius-like albuminous substance which he discovered in the mud composing the sea-bottom, at a depth of ninety or ninetyfive fathoms north of Smith Sound. The specimens of mud were brought up in a water-bottle apparatus, about a large spoonful being obtained each time of sounding. This mud was very sticky, and showed itself under the microscope to consist of a yellowish gray mass with numerous opaque lime particles embedded in it. If some of the mud was left to rest in a hollowed out glass slip for some time the albuminous masses exhibited unmistakable amœboid movements, and took into their substance particles of larmine. The substance is named Protobathybius.

We cannot follow the author further. His book is well worth reading, and only escaped notice here sooner through accident. It is well illustrated throughout. He takes exception on the ground of priority to the name Palæocrystic Sea, which Sir George Nares conferred upon the expanse which the Americans had previously named Lincoln Sea. He states that, owing to the neglect of his work by an assistant, numerous serious errors occur in the official volume of scientific results of the Polaris expedition already published, especially in the meteorological department. These are corrected in the appendix to the present volume, which contains also much other scientific matter. He finds fault throughout his book with the conduct of the ice-master of the Polar is, $\mathrm{S}$. O. Buddington, and considers that the ship might have reached higher latitudes if, on two occasions which he believes were favourable, a push had been made northward. He accuses Buddington of not even going up into the crow's-nest as often as he should have done to examine the state of the ice. Some official correspondence which passed on board the ship on these questions of the management of the expedition is given in the book. The manner in which the meteorological observations were kept up after the shipwreck, and the devotion with which Dr. Bessels attempted, though in vain, to sledge far north after the wreck from Polaris house are highly creditable.

The book is dedicated to the Arctic explorer, Capt. A. H. Markham, R.N., who with great kindness, and at very considerable inconvenience, shared his cabin on board the whaler Arctic with Dr. Bessels on the voyage to Dundee, the Ravenscraig having fallen in with the Arctic on the whaling-grounds.

H. N. MOSELEY

\section{THE COMET}

THE comet which, so far as we are yet informed, was 1 first astronomically observed in the southern hemisphere on May 29, is now well under observation in these latitudes, and as its position will become more and more favourable, it will be a mere question as to how long our telescopes will show it, what data may be obtained for an accurate determination of its orbit. The elements appear to have some resemblance to those of the great comet of I 807 , to which reference was made in Dr. Gould's early telegram from the observatory at Cordoba, but the identity of the comets appears highly improbable after Bessel's classical memoir containing a rigorous investigation of the orbit of the comet of 1807 , which he followed until the perturbations of the known planets had ceased to be sensible. We may briefly recall the circumstances attending the appearance of that body and one or two main results of Bessel's investigation. According to Piazzi it was first detected by an Augustine monk at Castro Giovanni in Sicily on September 9, but the first regular observation was made on the 22nd of the same month by Thulis at Marseilles From this time the comet's positions were determined at every opportunity by Bessel, Olbers, Oriani, and others until the end of February, I808, and on the I8th of the following month
Wisniewsky, favoured by a very acute vision and the clear skies of St. Petersburg, observed the comet again, and succeeded in fixing its position until the 27 th. In consequence of a notification from Olbers, that with powerful telescopes there might be a possibility of observing the comet again as the earth overtook it to some extent in October and November of the same year, Bessel, then working with Schroeter at Lilienthal, closely examined its track with reflectors of 15 and 20 feet focal length, and on November 9 did succeed in finding an extremely faint nebulosity near the computed place of the comet, which he could not find subsequently, but as the position differed I 2 ' from that assigned by an orbit which he considered very exact, he came to the conclusion that the object he observed was not the comet of 1807 , but another one which happened to be in the vicinity, and which was not seen elsewhere. The discussion of the six months' observations of the comet appears in the masterly treatise to which we have referred, viz., "Untersuchungen über die scheinbare und wahre Bahn des im Jahre 1807 erschienen grossen Kometen," published at Königsberg in 1810. The method of determining the perturbations of a comet due to planetary attraction, which is detailed in this memoir, was long practised by the German astronomers in similar cases.

Bessel inferred from his researches that at the perihelion passage of the comet on September 22 it was moving in an ellipse, with a period of revolution of I7 I4 years, which was reduced to 1685 years at the date of Wisniewsky's last observation, and continuing his computation of the perturbations to March, 1815, when the effect of planetary attraction had become very small, he found the period further reduced to 1543 years.

The general aspect of the comet now visible as viewed in an excellent Cometen-sucher, reminds us of the appearance of the comet of June, 1845 , discovered by Colla, which was observed under very similar circumstances, and it may be mentioned that Encke stated at the time that the comet of 1845 reminded him strongly of the great comet of 1819 , which passed across the sun's disk on June 26.

The present comet appears to have been at its least distance from the earth about June $2 \mathrm{I}$, and should soon present a material diminution of brightness. In perigee its distance would be about 0.3 .

[Since the above was in type we have received observations from Dr. Elkin, of the Royal Observatory, Cape of Good Hope : After a week of overcast sky the comet was found there on May 31. Mr. L. A. Eddie, F.R.A.S., of Graham's Town, saw it on May 27, and others claim to have seen it two days earlier. On June 4 the tail was $6^{\circ}$ long, coma 20 minutes, and nucleus 20 seconds in diameter; the comet was as bright as $a$ Columbæ.]

The following opinions of American astronomers have appeared in the Daily News. That paper, with wonderful journalistic enterprise, has not hesitated to telegraph nearly a column of matter from America on this subject :-

"Prof. Stone, of the Cincinnati Observatory, thinks it is not the comet of 1812 , because of its not moving in a southerly direction, but that it may possibly be that of I807. Professors Eastman and Skinner, at the Naval Observatory, succeeded in getting some fair observations of the comet on Friday night, although the night was not altogether favourable. Prof. Skinner describes the comet as having an extremely bright nucleus, which presented a very ruddy appearance. The observers did not know whether this appearance was normal, or was due to the prevailing atmospheric conditions. Prof. Skinner estimates the tail, which is fan-shaped, at about eight degrees in length. It was also ascertained that in twenty-two minutes the comet travelled three seconds in arc, and in an hour nine seconds, giving it a daily rate of travel northward of about three degrees thirty-six seconds. Computing its motion from its position when discovered, 
Prof. Skinner found that in two days and a quarter the comet moved about ten degrees. On Saturday morning it became distinctly visible at I 45 , and could be seen until the sun rendered invisible all the stars except Venus. The astronomers at the observatory maintain their opinion that this comet is identical with the one recently observed by Dr. Gould in Buenos Ayres. Prof. Skinner describes it as a much finer comet than Coggia's, which appeared in 1874 , and brighter than any since that which appeared in 1843 .

"Prof. Newcomb said that as all the observations made on the comet of 1807 showed it to have a period of nearly 1700 years, it seems out of the question that under any circumstances the same comet could have returned in so short a time as seventy-four years, unless it has passed in the vicinity of some larger planets, which it could not have done. From Dr. Gould's telegram it may be inferred that the comet was very near the orbit of that of 1807 when he observed it. Prof. Newcomb is inclined to think that it is a case of two comets moving in nearly the same orbit, rather than the return of the same comet. One reason for this is that if it had been a periodical comet returning every seventy-four years, it could not have failed to have been observed on former occasions, because it would have returned in 1734 and in 1760 . In neither of these years was any such comet observed. The position of its orbit is such that it could hardly have failed to be seen had it returned. Prof. Henry Draper has photagraphed the comet. To obtain such a photograph as he would like, he said, the plate ought to be exposed for at least an hour, but he had succeeded in getting an exposure of only seventeen minutes. The result, however, was satisfactory, in so far that it demonstrated the possibilities of photographing a comet. It showed the nucleus and the coma and part of the tail. He will try again to obtain a longer exposure. He wishes to take a larger photograph if possible, to examine more carefully the structure of the tail; but the larger the photograph, the more difficult it is to obtain, owing to the diffusion of the light. If he succeeds in obtaining two good photographs he will next turn his attention to its spectrum, which is much more difficult to photograph than the orb itself.

"Prof. Bois, of Dudley Observatory, at Allebuy, secured a number of valuable observations. He says that at two o'clock on Saturday morning its appearance both to the naked eye and in a telescope was magnificent. The head of the comet was very bright, and the tail thirty or forty minutes broad, extending nearly $20^{\circ}$ toward the North Star. The tail was very diffused and nebulous, spread out in fanlike form. Looking in the great telescope of thirteen inches aperture, a multitude of details became revealed which are not visible to the naked eye. The head was there seen to consist of a condensed nucleus, apparently about as large as Jupiter seen in a telescope, but of far greater intensity of light. A spray of brilliant rays spread out from the nucleus on the side nearest the sun, then, turning backward, mingled with the elements which form the tail. This resembled the jet of a fountain very closely in its general features. The tail itself extended in a direction diametrically opposite the sun. The whole field of the telescope was filled with glowing nebulosity. I am inclined to think that this comet has not been seen before this year, in modern times at least. It is probably the same comet as seen in South América. It is now certain that this is not the long-expected comet of 1882 . It is almost equally certain that it is not the comet of 1807 . The period of the comet of 1807 is about 1,700 years. Prof. Swift of Rochester says the comet grows smaller and brighter in nucleus, showing that it is approaching the sun. The head is active, and the tail does not ob- scure the stars. He thinks it will be visible several weeks. He cannot yet determine if the comet was ever before seen. Great activity is apparent in its head."

M. Janssen has presented to the Academy of Sciences, at its sitting of June 27 , the cliché of a photogram of the comet, which was taken with the large telescope he described a few weeks ago, constructed for the purpose of astral photography. He obtained also a series of photograms of the nucleus, for which he varied the time of exposure. The results prove that the brightness is not more than that of a star of the fifth magnitude. On the photograph, which will be printed in NATURE, and which our correspondent has examined, the stars are visible through the tail. M. Faye delivered a speech praising the success realised by his colleague, and remarking that it was the first time thit a comet had been photographed. The opinion that the tails of comets are merely an illusion, as professed by Seneca in his "Quæstiones Naturales," seems to gain ground, owing to the extraordinary transparency of these appendages.

WE have received the following communications :-

THE following positions which I obtained of the path of the comet may interest your readers :-I saw it first on

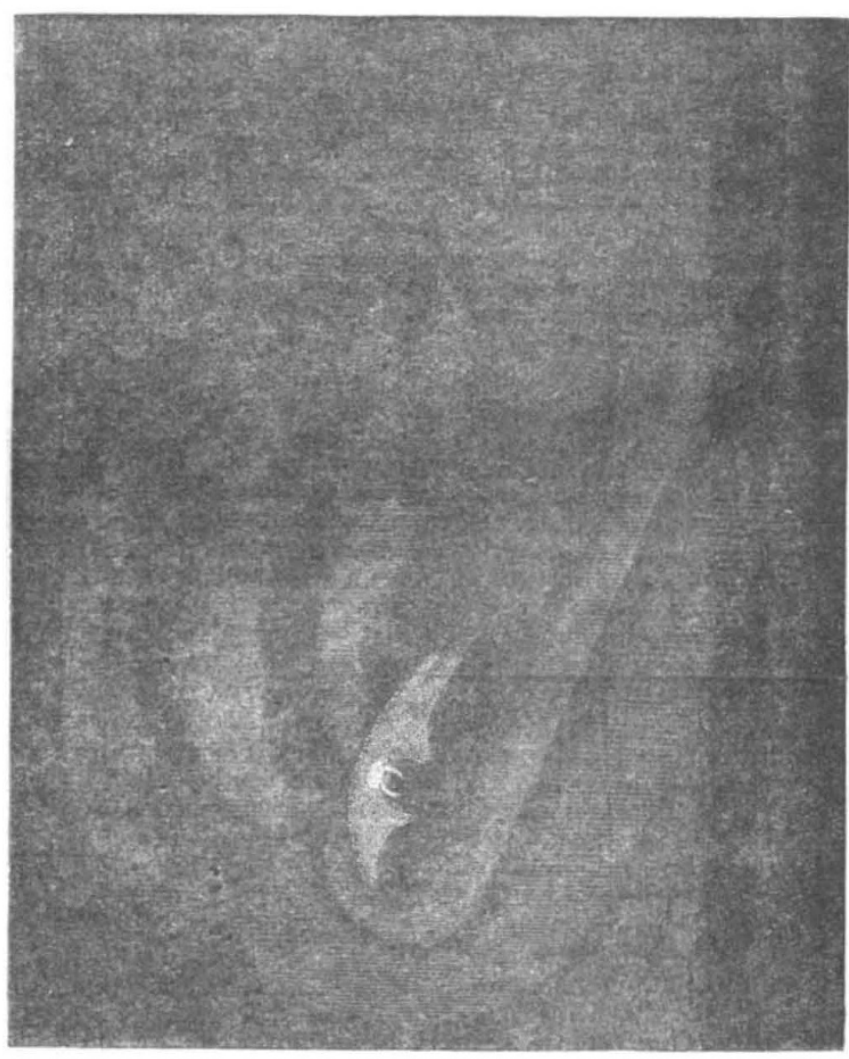

FIG. I.

Wednesday, June 22, at 10.55, during a break in the clouds for about a minute. It was then brighter than it was last night, the 27 th, when I saw it well, the sky being clear. The colour is of an orange tinge, and the tail extends to about $10^{\circ}$, but can only be seen so far by sweeping across it. It has changed wonderfully since I first observed it, as will be seen by the drawings which I send you. The No. I Drawing shows a most singular appendage round the nucleus, in shape like a milkmaid's yoke, the nucleus occupying the hollow, which was black. From the nucleus two horns projected; they were as bright as the nucleus. 
The" first envelope on the preceding side took a sudden bend from the circular form to a straight line, while the outer envelope retained its parabolic form.
Last night, the 27 th, I was surprised to find a great change had taken place-the yoke-shaped centrall luminosity appeared as if it had turned round in the nucleus

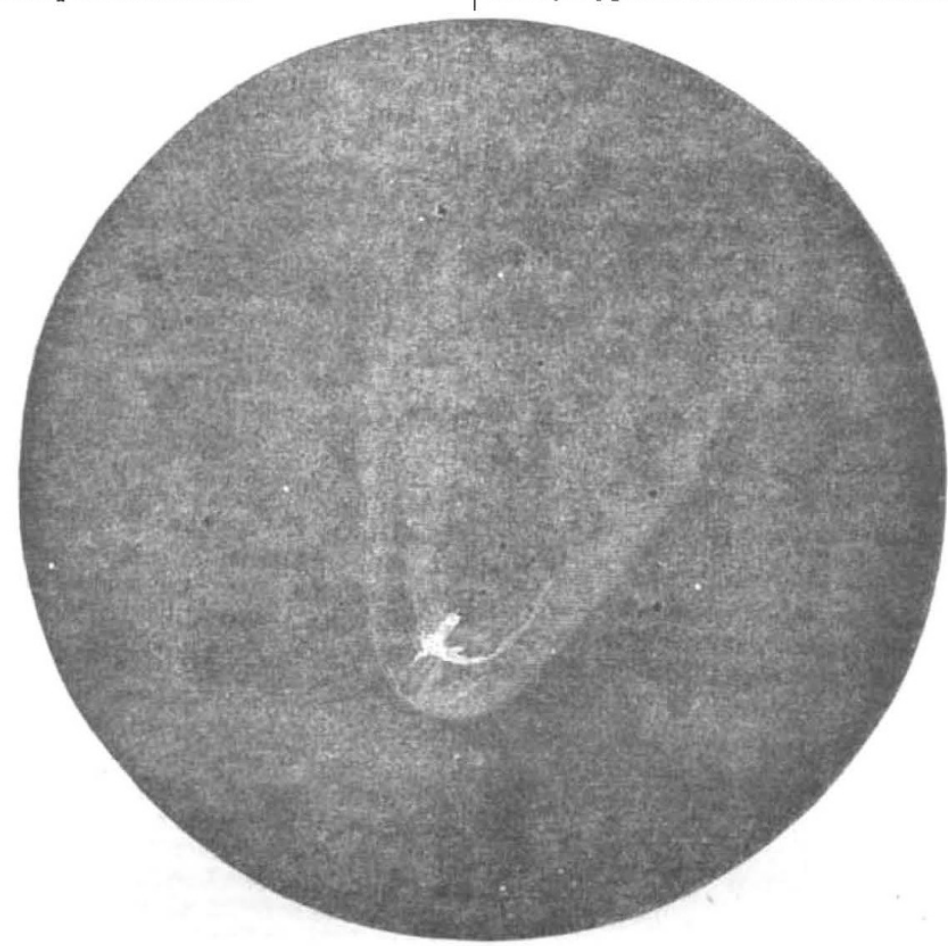

FIG. 2.

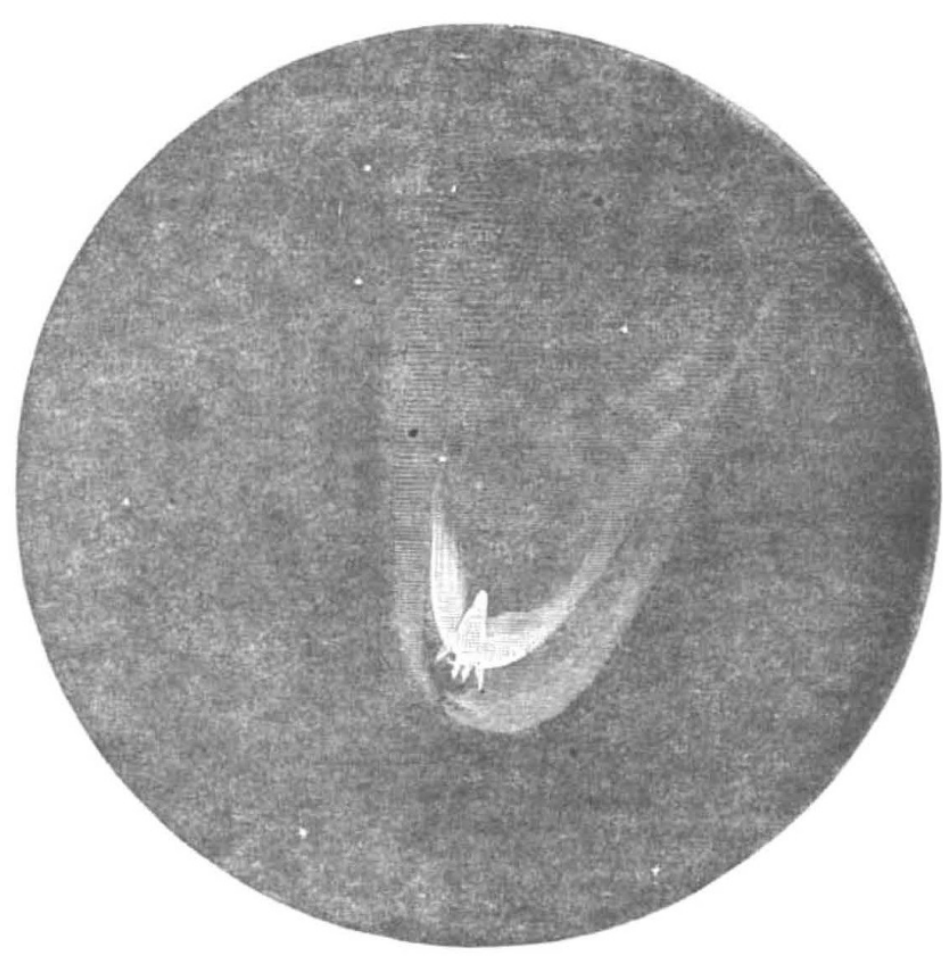

FIG. 3.

and occupied the usual position, while the nucleus itself $\mid 2,3)$. The outer envelope on the following side was inter had thrown out a bright tail, which gave it the appearance rupted in its continuity, or seemed wanting.

of a small comet lying across the bright envelope (Figs. 1 The positions I got are as follows:- 


\begin{tabular}{|c|c|c|c|c|c|c|}
\hline & & h. m. & & $\begin{array}{l}\text { R.A. } \\
\text { h. m. s. }\end{array}$ & & $\begin{array}{c}\text { N.P.D. } \\
\circ\end{array}$ \\
\hline June 23 & $\ldots$ & II 0 & $\ldots$ & $\begin{array}{lll}533 & 59\end{array}$ & $\cdots$ & 4455 \\
\hline 25 & $\ldots$ & 100 & $\ldots$ & $54 I \quad 4 I$ & $\ldots$ & 3652 \\
\hline 27 & $\ldots$ & 100 & $\ldots$ & 55034 & $\ldots$ & 2950 \\
\hline 27 & $\ldots$ & 120 & $\ldots$ & 55554 & $\ldots$ & 2942 \\
\hline
\end{tabular}

so that last night it crossed the path of Brorsen's comet of April 30, 1879.

Ferndene, June 28

\section{Photographic Spectrum of Comet}

On Friday night (June 24) I obtained, with one hour's exposure, a photograph on a gelatine plate of the more refrangible part of the spectrum of the comet which is now visible. This photograph shows a pair of bright lines a little way beyond $\mathrm{H}$ in the ultra-violet region, which appear to belong to the spectrum of carbon (in some form) which I observed in the visible region of the spectra of telescopic comets in I866 and I868. There is also in the photograph a continuous spectrum in which the Fraunhofer lines can be seen. These show that this part of the comet's light was reflected solar light.

This photographic evidence supports the results I obtained in 1868 , showing that comets shine partly by reflected solar light, and partly by their own light, the spectrum of which indicates the presence in the comet of carbon, possibly in combination with hydrogen.

\section{Upper Tulse Hill, June 27 WILLIAM HugGins}

COMET I88 I $b$ was well observed at the Royal Observatory, Greenwich, on June 24 and 25 . Its position was determined on both evenings with the altazimuth and transit-circle. The following are the places deduced from the meridian observations (uncorrected for parallax and aberration) :-

$$
\begin{array}{cc}
\text { G.M.T. } & \text { R.A. } \\
\text { h. m. s. h. m. s. } & \text { h. }
\end{array}
$$

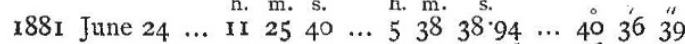

$$
\begin{array}{lllllllllllllll}
25 & \ldots & \text { II } & 25 & 55 & \ldots & 5 & 42 & 51 & 506 & \ldots & 36 & 39 & 30
\end{array}
$$

The observation on June 25 indicates the following corrections to the ephemeris computed by Mr. Lobse from the elements communicated by the Emperor of Brazil (Dunecht Circular, No. 21) :-Correction in R.A. +9 m., in Dec. $+6^{\circ} 23^{\prime}$. On June 24 the head was estimated to be brighter than Vega or Arcturus, notwithstanding its low altitude, and on June 25 it appeared decidedly brighter than Arcturus, the star being at about $10^{\circ}$ greater altitude than the comet. The tail, which was slightly curved (convex towards the preceding side), was traced to a distance of about $8^{\circ}$ on June 24 , and $10^{\circ}$ or more on June 25 , its general direction pointing to the star 2 Ursæ Minoris, about $3^{\circ}$ east of Polaris. With the Sheepshanks equatorial (63 inches aperture) the head showed the want of symmetry that has been remarked in some other comets. On June 24 the preceding side was much the brighter, there being a strong brush or arc of light on that side, with a bright fan close to the nucleus and a much smaller arc on the following side, the two arcs appearing to spring from the nucleus on opposite sides, and higher up to interlace. A very remarkable feature was a straight wisp of light extending from the nucleus nearly along the axis of the tail. On June 25 this had become much less striking, and the appearance of the head had entirely changed. The following side was then much the brighter, and the general appearance was that of a parabolic envelope, with a much brighter unsymmetrical parabola placed within it, the latter having its focus on the following side of the nucleus, and its axis turned round in the direction $n p s f$ from that of the tail.

The greater part of the head gave a bright continuous spectrum, obliterating the usual cometary bands, but one portion showed three bands, in the green, blue, and violet respectively. Measures of the principal band in the green showed that it coincides with the band in the first spectrum of carbon (blue base of flame) at 5165 , and not with that of the second spectrum (vacuum-tube) at 5198 .
The bands in the blue and violet appeared to correspond, as nearly as could be estimated, with bands in the first spectrum of carbon. These observations were made with the half-prism spectroscope mounted on the $12 \frac{3}{4}$-inch equatorial, a dispersive power of about $18 \frac{1}{2}^{\circ}$ from $A$ to $H$ being used, with a magnifying power of 14 on the viewtelescope, as in the measures of star-motions in the line of sight. No decided polarisation was detected either in the head or the tail. Cloudy weather has prevented any observation of the comet since June 25 .

Royal Observatory, Greenwich, June 28 W. H. M. CHRISTIE

IN a letter to the Times of the 25 th inst., Mr. Ranyard says of Comet $b \mathrm{I} 88 \mathrm{I}$, at present visible in the northern heavens :-- "In general brightness it decidedly outshone the star Capella. ... With a direct-vision spectroscope of five prisms, and a $3 \frac{1}{2}$-inch telescope, its nucleus and head gave a continuous spectrum, on which I could not detect any bright bands." Last night, June 27, shortly before midnight, the brilliancy of the nucleus had considerably decreased, and yet with a five-prism direct-vision spectroscope I could see most clearly, along with the continuous spectrum, three green bands, not only in the nucleus, but also in the surrounding coma. Two of the bright lines were still strong in the neighbourhood of the nucleus, even where the continuous spectrum was very faint. I used an ordinary Browning spectroscope on an 8-inch achromatic. A small McClean's spectroscope gave only the continuous spectrum, as seen by $\mathrm{Mr}$. Ranyard. This was, I think, due merely to the brightness of the continuous spectrum; for in the Browning instrument the bright lines over the continuous spectrum were not very conspicuous with a wide slit, but on narrowing the slit the green bands became much brighter than the rest of the spectrum.

On June 25 the night was rather cloudy, but good observations for position were obtained by observing the transit of the comet and of $\delta$ Aurigæ over the wires of an eyepiece of the equatorial. The mean of four wires gave R.A. 5h. 42m. 5' 34 s., at G.M.T. 12h. Irm., the North Declination being $53^{\circ} 30^{\prime} 57^{\prime \prime} \cdot 6$.

On June 27 , towards midnight, the double envelope surrounding the nucleus was clearly defined in the telescope, as was also the bright bundle of rays, which spread out in the direction of the sun and extended to a point in the coma about half way between the bounding lines of the inner and the outer envelopes. The direction of these bright rays, which were very vivid, was not quite opposite the direction of the tail, and the latter was very slightly curved.

A transit of the comet, sub Polo, was observed last night, June 27 , at G.M.T. I Ih. $38 \mathrm{~m}$., and this, combined with the corrected reading of the meridian circle, gives the following position:--R.A. 5h. $52 \mathrm{~m}$. 46.3 Is., North Declination $60^{\circ} \mathrm{I}^{\prime} 40^{\prime \prime} \cdot 6$. The length of the tail, clearly discernible to the naked eye, was last night about $9^{\circ}$.

Stonyhurst Observatory, Whalley, June 28 S. J. PERRY

THE following places have been obtained with the transit-circle when the comet passed sub Polo:-

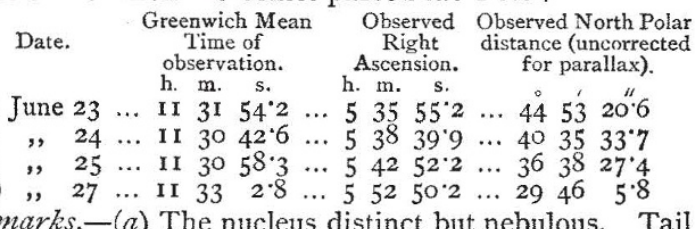

Remarks.-(a) The nucleus distinct but nebulous. Tail

bright, and estimated $15^{\circ}$ in length. Observation good.

(b) Observation difficult, owing to cloud.

(c) Nucleus better defined than on June 23, but not so bright. Length of tail estimated at $15^{\circ}$. Observation good. (d) Observation fair, very cloudy. Tail $12^{\circ}-15^{\circ}$ in length Radcliffe Observatory, Oxford $\quad$ E. J. STONE 
THE comet was examined spectroscopically here last night at $I 1 \cdot 30$. The nucleus gave a bright continuous spectrum, while the coma and brighter portions of the tail gave the three least refrangible hydrocarbon bands superposed on a faint continuous spectrum. On moving the slit of the spectroscope towards the fainter part of the tail the bands died out, leaving a faint continuous spectrum, which again gradually faded away as the end of the tail was approached. I have not measured the position of the bands, but they are sensibly the same as those from an alcohol flame. GEORGE M. SEABROOKE

Temple Observatory, Rugby, June 28

\section{NOTES}

ThE Lords of the Committee of Council on Education, in reply to an application for aid to science teachers attending the classes of the Mason Science College two days a week, agree to pay three-fourths of the fees for the chemical and physical laboratories and for biology and histology, for a limited number of teachers, on condition that satisfactory terminal reports of their progress (ascertained by examination) and of their conduct be received at the end of the Michaelmas, Lent, and Easter terms. Applications for the privilege must be made to the Secretary, Science and Art Department, not later than August 3I. The selection will rest with that Department. One-fourth of the fee for the whole session must be paid by the student on entrance; and the remaining three-fourtbs will be paid by the Department in equal instalments at the commencement of each term, if the reports are satisfactory.

The fine library of the late M. Chasles is to be sold by public auction between June 28 and July $\mathrm{r} 8$. It contains no fewer than 3936 works, or about 15,000 volumes, and is one of the most complete libraries of mathematical works in existence. The precious manuscripts and various works of history and philology will doubtless be eagerly sought by amateurs. There is, among other works, a Geography of Ptolemy of Alexandria, printed at Rome in 1490 , containing geographical maps which are the first engraved with copper plate (1478). The collection includes eighteen different editions of Archimedes, and the works on Euclid number sixty-six. The astronomical works of the sixteenth, seventeenth, and eighteenth centuries are fully represented, as also those on astrology, alchemy, \&c.

THE programme of an excursion by the Geologists' Association to the Lake District, from Monday, July I8, to Saturday, July 23, has been issued. Keswick will be the centre of operations till Friday, when the Grasmere and Ambleside district will be visited. Saturday will be given to Windermere.

WE have also before us an attractive programme of a marine excursion to Oban and the West Highlands of Scotland by the Birmingham Natural History and Microscopical Society. The party leave Birmingham on the evening of July $\mathrm{r}$, and go direct by Greenock and the Kyles of Bute to Oban, which is made the centre for various excursions by sea or land, till July 12. Facilities for dredging will be afforded. The party will include some able naturalists.

IN a recent issue we gave some account of the Ben Nevis Observatory (so-called). The system has been in operation since June I, and the daily observations by Mr. Wragge are published in the Times. This gentleman begins his magnanimous toil up the hill every morning at 5 o'clock. After spending about an hour on the top (9 to 10 ) in taking observations with the scanty stock of instruments fixed on stands protected by a stone screen, he gets home again by about $\mathbf{2}$ in the afternoon. In the early part of June the path up the mountain was often deep in snow and enveloped in mist, but $\mathrm{Mr}$. Wragge has marked out the track with a succession of cairns. Anything more disgraceful to British science than this state of things, as representing our present achievement in the way of regular mountain-observations, it is difficult to conceive! A comparison with what has been accomplished in other countries, notably America, where well-equipped observatories are now to be found at vastly greater heights than the top of Ben Nevis, is sufficiently humiliating for us.

THE May number of Naturen gives the first of a series of papers, by Prof. Axel Blytt, on the "Theory of the Immigration of the Norwegian Flora at Different Earlier Geological Periods." In this paper the author, who is well known as the highest authority among Scandinavian botanists, describes the character of the flora, which, considered generally, is represented by only a small number of genera. At an elevation of $4000-4500$ feet above the level of the sea the interior and southern districts exhibit dwarf forms of the willow and birch, with juniper; between 3000-3500 feet the first birch woods appear in the same districts, while firs and pines begin a few hundred feet lower. Here and there the high and barren fjalds of the interior near the glaciers are broken by the occurrence of blooming oases of plants of Arctic continental forms, which, after having lain buried for months under the snow, awaken to new life with the return of the summer sun. To the interior also belongs a boreal flora of small deciduous trees, including the oak, asb, alder, lime, \&c., which penetrate as far as 2000 feet, and in the Inner Sogu district occur the only woods of elm and wild cherry to be found in Norway. The subboreal belt, including several Spiræas, Fragaria collina, Artemidia campestris, Thymus chamadrys, \&c., is limited to the Lower Silurian formations in the eastern districts. The western coast-lands between Stavanger and Christiansund are the habitats of an Atlantic flora, including Erica tetralix, and several of the rarest Norwegian plants, but here Calluna, Sphagna, and Carices, with turf beds, constitute the principal forms. The most southern littoral belt near Christiansund presents a sub-Atlantic flora, while a number of sub-Arctic forms appear scattered over the whole of Norway. Prof. Blytt considers that the sporadic occurrence of the various continental and insular forms of the flora of Norway points to the conclusion that the climate has undergone variuus secular changes since the Glacial period, the continental forms having immigrated duri ig the continuance of drought, when the peninsula was connected with neighbouring continents, while the appearance of the insular forms was contemporaneous with rainy periuds.

THE decree appointing sixty-five French members of the Congrès d'Électricité has been signed, by the President of the Republic, and will soon be published. Foreign Governments will appoint all their own members. Reporters and the public will not be admitted to the Congress; an official report will be published by the general Committee. Some French papers have already condemned such practice in strong terms. No jurymen will be appointed by the exhibitors, and the latter will have no direct influence on the verdicts. It is proposed to consult the Congress on certain measures of general interest, e.g. the adoption of electrical units. The electric railway station will be placed inside the building. For want of time, no viaduct will be constructed, and the rails will be laid on the common roads. The space allotted to English exhibitors on the ground-floor has been largely occupied. In addition to this space each of the British light exhibitors will have on the upper floor a special saloon to illuminate with his own system. The right of publishing and selling the French Catalogue has been purchased by the printers and publishers of La Nature, rue de Fleurus. The sale of scientific papers will be authorised, but will take place exclusively through their agency.

IN an old book-"Thomæ Bartolini Acta Media et Philosophica Hafniensa Anno 1674, 1675, et 1676," Herr Budde has 